Journal of Engineering Science and Technology Review 5 (4) (2012) $35-37$

Special Issue on Renewable Energy Systems

Research Article
JOURNAL OF

Engineering Science and

Technology Review

www.jestr.org

\title{
The Wireless Albedometer
}

\author{
D. T. Cotfas* and P. A. Cotfas
}

Transilvania University of Brasov, Romania

Received 5 August 2012; Revised 25 September 2012; Accepted 10 October 2012

\begin{abstract}
The wireless albedemeter as a new solution for the measurement of the albedo is presented in this paper. The classica pyranometers which are used to build the albedometers were replaced with two small monocrystalline silicon photovoltaic cells. The mobility and applicability of the albedometer increase using the device called Tag $4 \mathrm{~m}$ instead of the classical acquisition board.
\end{abstract}

Keywords: Albedometer, photovoltaic cells, wireless, Tag4m, router.

\section{Introduction}

The solar radiation has several components. The global horizontal solar radiation is composed of the diffuse horizontal solar radiation and the direct solar radiation. If the surface is tilted the third component appears - the reflected solar radiation.

The reflected solar radiation is very important for the energy balance. A new size - albedo has to be introduced if this type of solar radiation is taken into account.

There are many definitions for the albedo in function of the reflecting surface and the research domain: ground albedo, crop albedo, etc. In general the definition for the albedo is the ratio between the reflected radiation of surface $\mathrm{R}$ and the global horizontal solar radiation $\mathrm{G}$, see Eq. 1 .

$a=\frac{R}{G}$

The albedo is an important parameter for different research domains, such as: the atmospheric sciences, the agriculture, the bio-geo engineering, the photovoltaic domain, climatology, the forestry and the building energy science. Taking into account the climatic changes and not only, albedo becomes a crucial parameter [1]. There are many researchers who claim that by controlling the crop canopy albedo, the warming can be averted. Increasing the crop albedo with $\sim 0.04$ can lead to a cooling effect with $\sim 1 \mathrm{oC}$ for Europe in summer [2-5].

\section{Methodology}

There are three methods to measure the albedo: from the top

*E-mail address: dtcotgas@unitbv.ro

ISSN: 1791-2377 @ 2012 Kavala Institute of Technology. All rights reserved. of the atmosphere using planes, meteorological balloons or satellites [6,7], in the lab [8] and in the field conditions [9].

The first method is suitable to measure the albedo for the large area and homogenous surfaces. This method is not recommended for small surfaces. The influence of the atmospheric factors should be taken into account in this case.

In the lab the albedo can be measured only for small samples. In this case the light source can be a problem. In the lab the light source must be a solar simulator to assure a very good matching between the spectrum of the light source and the solar spectrum. The price of the solar simulator is very high and it grows with the increase of the illuminated area. Another problem for the lab measurement is the area of the albedometer. The area of classical pyranometers which are used for albedometers is high and the shadow can cover the entire illuminated area. A good solution can be using the two small photovoltaic cells.

The third method is the most widely used because the measurements are performed in the real conditions.

The albedometers can be realized using one or two back to back pyranometers. In the first case the cost is lower than in the second when two pyranometers should be used. The measurements for the albedometer with one pyranometer are performed step by step. The reflected radiation of the target surface is measured first, and the global horizontal solar radiation is measured after the pyranometer rotation with $180 \mathrm{o}$. There is a big disadvantage; the two radiations are not measured simultaneously. If the level of radiation is changed due to the clouds, the measurements are not accurate. In this case the measurements should be performed in clear sky conditions. Using the two pyranometers positioned back to back can eliminate the disadvantages above raising the measurements' accuracy but the costs become considerably higher. To reduce costs pyranometers of inferior class can be chosen if the measurements accuracy allows it [1]. 


\section{The albedometers}

The cost can be considerably reduced if two small photovoltaic cells are used instead the two pyranometers. The spectral response of photovoltaic cells can be a problem, but using the calibrated solar cells in function of the global horizontal solar radiation and the diffuse solar radiation can solve this problem.

The first albedometer with photovoltaic cells has the following components [1], see Fig.1:

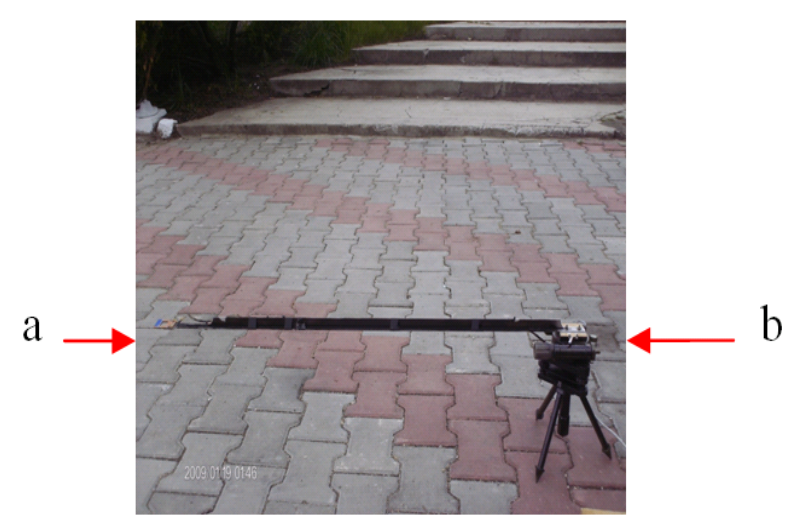

Fig.1 The first albedometer

a) The sensor system - two solar cells and the correction system for temperature. The photovoltaic cells used are monocrystalline silicon, with dimensions $1 \mathrm{~cm} / 3 \mathrm{~cm}$ placed back to back at a small distance one from the other, they won't influence each other. The temperature correction is performed using two temperature sensors, one for each photovoltaic cell. Initially the temperature coefficient of the short circuit current for silicon solar cells has been determined.

b) Support system - assure the horizontality.

c) Data acquisition board - NI 6036 which is dedicated to laptop. It had a resolution of 16-bit, this providing a high accuracy for the measurements.

d) Portable PC - with a soft dedicated to data acquisition and processing realized in graphical program language LabVIEW. It assures a high mobility for the measurements.

Even with the first type of albedometer which is mobile a problem appears when different small surfaces have to be measured as in agriculture. For the testing small surfaces were sown with different varieties of wheat. For monitoring of the crop albedo for these small surfaces in different time periods and simultaneously, a wireless albedometer was designed. For multiple surfaces measurements a matrix composed of these wireless albedometers can be realized. For this matrix one router or one access point and only one computer are sufficient.

The components of the wireless albedometer are largely similar with the components of the first albedometer but they are improved, see Fig. 2.

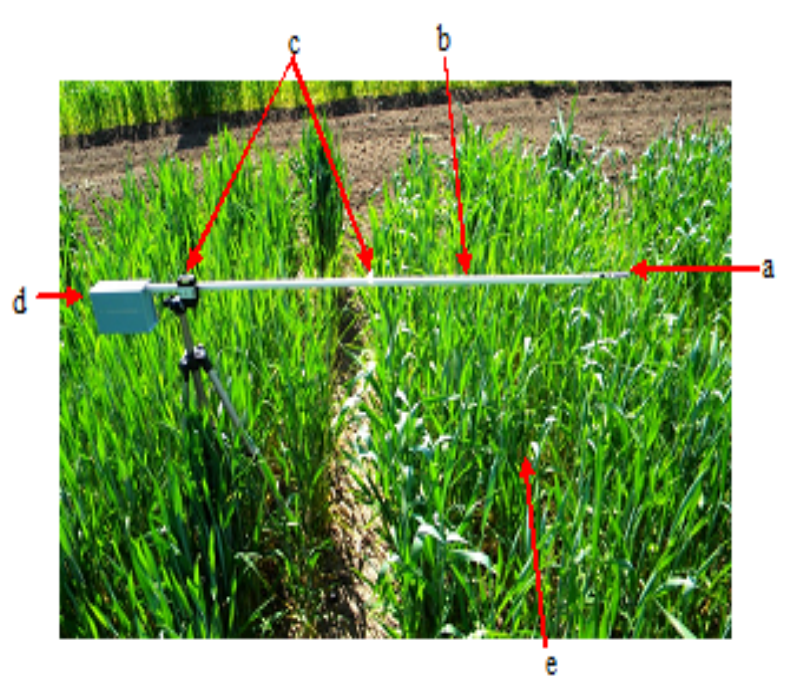

Fig. 2. The wireless albedometer in wheat cultivar

The sensors system (a) is improved by reducing the area, a new positioning and a new fixing system. The photovoltaic cells' temperature is measured more accurately due to the sensors' positioning and by using the temperature sensors with less than $10 \mathrm{C}$ error. The support for the sensors and the system (b) allows horizontal positioning using two perpendicular sensors (c). Also the new support ensures a variable positioning at different heights. This facility allows measuring the albedo relatively easy for different surfaces, as well as for the different cultivars (e - wheat), walls, photovoltaic panels and others.

The acquisition board was replaced with the Tag4M placed in a box (d). It is an acquisition board and a wireless device. This acquisition board has four measurement channels, two for the measurement of the short circuit currents of the photovoltaic cells and two for the photovoltaic cells temperature. The short circuit currents are measured as a drop voltage on the two resistors. The values of the resistors were previously measured very precisely. Another very important improvement is that this board covers distances of up to $800 \mathrm{~m}$ in open field, making it a useful tool for stand alone devices. For the router rechargeable batteries can be used as power supplies. The communication between the Tag4M and the router is easy to realize.

\section{Results and Discussion}

The measurements were made for different types of surfaces. Also the measurements were performed for different types of cultivars.

The measurement accuracy can be improved if taken into account the correction factor for shadowing. This correction factor can be calculated using the following equation:

$$
C_{a}=\frac{1}{1-\left(F_{c}+F_{s}\right)+K_{d}\left(F_{c}+F_{s}\right)}
$$

where $\mathrm{Kd}$ is the ratio between the diffuse radiation and global horizontal solar radiation Eq. 3, Fc is the view factor for the portion of the sample area shaded by the solar cells, Fs is the view factor for the portion of the sample area 
shaded by the support rod. The two factors Fc and Fs can be calculated using the simplified equation, Eq. 4, $[9,10]$.

$$
K_{d}=f\left(K_{t}\right), \quad K_{t}=G / G_{e x t}
$$

where Gext is the extraterrestrial radiation which is calculated by software and $\mathrm{f}(\mathrm{Kt})$ is the model implemented in the software [1].

$$
F_{c}=\frac{4}{\pi}\left(\frac{l h}{l^{2}+h^{2}} \tan ^{-1}\left(\frac{l h}{l^{2}+h^{2}}\right)\right)
$$

where 21 represents the width of the shadow area of sensor or support when the zenith angle is zero and $\mathrm{h}$ is the distance between the surface and the sensors.

The value of the corrected albedo can be calculated using the following equation:

$a_{c}=a C_{a}$

where a is the uncorrected value of albedo calculated with Eq. 1 and $\mathrm{Ca}$ is the shadow correction factor calculated with Eq. 2.The soft created in LabVIEW allows the data acquisitioning, the corrections that have to be made function of the solar cells temperature. Afterwards, knowing the shadowing area, the correction in function of the shadowing should be made using Eq. 2 and Eq.5.

The values of the albedo for several types of surfaces are presented in Table 1.
Table 1. The values of albedo for different type of surfaces

\begin{tabular}{l|c}
\hline \multicolumn{1}{c|}{ The type of surfaces } & The values of albedo \\
\hline $\begin{array}{l}\text { Moist soil } \\
\text { (dark) }\end{array}$ & $0.59 \pm 0.03$ \\
Green grass & $0.52 \pm 0.01$ \\
Wheat - ARDS Turda & $0.257 \pm 0.02$ \\
Wheat - NARDI Fundulea & $0.223 \pm 0.03$ \\
& \\
The polycristaline silicon solar cell & $0.088 \pm 0.04$ \\
\hline
\end{tabular}

The measurements were performed in clear sky conditions. The period time was five minutes and the values presented in Table 1 are the average values.

\section{Conclusions}

A new type of wireless albedometer was presented, using two small monocrystalline silicon photovoltaic cells with an area of $3 \mathrm{~cm} 2$.

The new type of albedometer assures a very good mobility and the possibility to realize an array of albedometers at very low prices and a good accuracy.

This albedometer is very suitable to realize measurements in research domains such as agriculture, for small area and in lab measurements.

The software program realized in LabVIEW allows performing to the corrections in function of the temperature using the temperature coefficients of the photovoltaic cells previously determined and for the shadow area after the measurements.
1. D. T. Cotfas, S. Kaplanis, P. A. Cotfas, D. Ursutiu, C. Samoila, World Renewable Energy Congress X, Glasgow, Scotland, (Proceedings of the World Renewable Energy Congress - WREC X, ISBN 978-008-056-8973), pp. 2028 - 2033 (2008).

2. J. S. Singarayer, A. Ridgwell, P. Irvine, Environmental Research Letters 4, 045110 (2009).

3. A. Ridgwell, J. S. Singarayer, A. M. Hetherington, P. J. Valdes, Current Biology 19, 146 (2009).

4. H. D. Matthews, A. J. Weaver, M. Eby, K. J. Meissner, Geophysical Research Letters, 30 27-1 (2003).

5. A. Blum, Australian Journal of Agricultural Research, 561159 (2005).
6. B. Pinty, M. M.Verstraete, N. Gobron, F. Roveda, Y. Govaerts, J. V. Martonchik, D. J. Diner, R. A. Kahn, International Geoscience and Remote Sensing Symposium (IGARSS), Sydney (2003).

7. W. Zhao, M. Tamura, H. Takahashi, Remote Sensing of Environment, 76 202, (2001).

8. P. Berdahl, S. E. Bretz, Energy and Buildings, 25149 (1997).

D. J. Sailor, K. Resh, D. Segura, Solar Energy, 80589 (2006).

9. A. D.Matthias, L. Accioly, A. K. Batchily, L. G. Ferreira, A. Fimbres, E. E. Sano, D. F. Post, Soil Science Society of America Journal 641035 (2000). 